\title{
Optimizing Ophthalmic Delivery of a Poorly Water Soluble Drug from an Aqueous
}

In situ gelling system

F. G. Senjoti, P. Timmins, B. R Conway, and A. M. Smith*

Department of Pharmacy, School of Applied Sciences, University of Huddersfield, Queensgate, Huddersfield, HD1 3DH, UK.

*Correspondence:

Prof. Alan M. Smith

Tel: +44-1484-472-305

Fax: +44-1484-472-305

a.m.smith@hud.ac.uk 


\section{Abstract}

Poorly soluble drugs are often unsuitable to incorporate in ocular in situ gelling systems due to the aqueous based gelling formulations and low volumes administered. For such formulations to be successful, the administered drug must have sufficient solubility to diffuse from the formulation to the eye and should not affect the gelation of the in situ gelling material. Drug salt forms can improve the solubility of poorly soluble drugs, however, as in situ gel forming formulations are often designed to be crosslinked by salts (present the lacrimal fluid) it can make salt forms difficult to formulate. The aim of this study was to develop an in situ gel forming ophthalmic formulation of a poorly soluble drug flurbiprofen (FBP) through cyclodextrin complex formation and to analyse the impact on gelation, release and permeation through the cornea. Hydroxypropyl-beta-cyclodextrin $(\mathrm{H} \beta \mathrm{CD})$ was used as a complexing agent and low acyl gellan gum was added to the FBP- HßCD complex as a water soluble in situ gelling polymer. Measurements were performed using rheo-dissolution, which utilises a rheometer with a modified lower plate that has the unique ability to allow rheological measurement and analysis of drug release simultaneously. An ex-vivo permeation study was also performed using porcine cornea. Rheological measurements in terms of elastic $\left(\mathrm{G}^{\prime}\right)$ and viscous $\left(G^{\prime \prime}\right)$ modulus showed rapid gelation of the formulation upon contact with simulated lacrimal fluid (SLF). Approximately, 97\% FBP was released when 10\% HßCD was used and release was decreased to $79 \%$ when the amount of $\mathrm{H} \beta C D$ was increased to $20 \%$. The percentage of drug permeation through the cornea was $55 \%$ in 300 min whereas the marketed non gelling eye drop formulation containing FBP sodium showed only $37 \%$ permeation. The data presented here, revealed that not only could a poorly soluble drug be complexed with cyclodextrin and loaded into an in situ gelling system without interfering with the gelation, but also permeability the of the drug improved. 


\section{Introduction}

Improving the bioavailability of the therapeutics for ophthalmic delivery has been a major research focus over the past few decades. The distinctive anatomy and physiology of the eye make improving bioavailability of ophthalmic drugs one of the greatest challenges in drug delivery, whether that be delivering to the anterior or posterior regions of the eye. One of the best strategies to improve ocular bioavailability is to use in situ gel forming ophthalmic drug delivery systems. These dosage forms exhibit pseudoplastic flow behaviour to aid dispensing and then undergo an in situ sol-gel transition, which reduces clearance from blinking and nasolacrimal drainage, resulting in a prolonged retention time [1-3]. Poorly soluble drugs however, are generally unsuitable for incorporation in such delivery systems due to the aqueous based gelling formulations, making it difficult to dissolve the full dose in the low volumes administered in eye drop formulations. The polysaccharide gellan gum is one such in situ gel former that forms strong gels on exposure to monovalent and divalent cations $\left(\mathrm{K}^{+}, \mathrm{Na}^{+}, \mathrm{Ca}^{2+}\right.$ and $\mathrm{Mg}^{2+}$ ) that are found in sufficient concentrations in lacrimal fluid. It is currently used in the marketed in situ gelling formulation Timoptol ${ }^{\circledR}$ LA to increase retention time on the surface of the eye, improving the delivery of the water soluble drug timolol maleate for the treatment of glaucoma. For such formulations to be successful, the administered drug must have sufficient solubility to diffuse into the eye [1,4] (with the ideal drug having both lipophilic and hydrophilic properties) and should not interfere with the performance of the in situ gel former. Hence poorly soluble drugs are not usually used in such formulations, despite the potential useful therapeutic effect of the drug. In addition, drug salt forms which can improve the solubility of a poorly soluble drugs can interact with gellan gum increasing the viscosity or even inducing gelation before administration. Flurbiprofen (FBP) is an example of such a drug. It is an aryl propionic nonsteroidal anti-inflammatory drug (NSAID) having analgesic, antiinflammatory and antipyretic properties. According to the Biopharmaceutical Classification 
System (BCS), FBP is considered as a Class II drug exhibiting high permeability and low water solubility [5]. FBP is used as the sodium salt in anti-inflammatory eye drops (marketed as Ocufen $^{\circledR}$ ) to enhance the solubility. This salt form however is difficult to formulate as an in situ gel forming formulation using gellan gum because of the tendency of the polymer to crosslink with sodium ions.

A number of other strategies have been employed to increase the solubility of poorly soluble drugs, such as, use of solubilizing systems such as liposomes and microemulsions to increase the solubility in the aqueous tear fluid, formulating as nanogels to enhance the residence time on the surface of the eye [4] and use of drug-cyclodextrin inclusion complexation to enhance the aqueous solubility, stability and bioavailability of ocular drugs [6,7]. Cyclodextrin (CD) complexation in particular, has been successfully employed in recent years and not only have shown to improve solubility but also can increase the rate of dissolution [5]. Moreover, a recent study by Jansook et al (2019) demonstrated increased transcorneal permeation of the NSAID celecoxib using mucoadhesive polymers containing CD nanoaggregates [8]. CDs are cyclic oligosaccharides having hydrophobic/lipophilic internal cavity and hydrophilic outer surface. The hydrophobic cavity allows poorly soluble drug molecules to enter and formation of inclusion complex without forming any covalent bonds [5,9]. Amongst all cyclic oligosaccharides, $\mathrm{H} \beta C D$ is the most commonly applied $\mathrm{CD}$ in ophthalmic formulations. $\mathrm{H} \beta \mathrm{CD}$ is well tolerated, even at concentration as high as $45 \%$ in humans and animals $[7,10]$.

Here we have investigated flurbiprofen (FBP) which is a poorly soluble drug but shows increased solubility in buffered solution ( $\mathrm{pH}$ 7.4) [11]. Formulating the in situ gelling formulation of FBP in a buffer solution, may however, cause the premature gelation of the gellan, due to its ability to form a solid gel when exposed to low concentrations of group 1 and group 2 metal ions. So a drug-cyclodextrin inclusion complex was created using 2hydroxypropyl- $\beta$-cylodextrin $(\mathrm{H} \beta \mathrm{CD})$ that could be dissolved in gellan gum without addition 
of salts to formulate an in situ gelling formulation. Simultaneous measurements of rheology and drug release were performed using a rheo-dissolution cell developed in our laboratories [12] and a drug permeation was measured through an ex-vivo corneal model.

\section{Martials and Methods}

\subsection{Materials}

FBP, $H \beta C D$, low acyl gellan gum (Gelrite $®)$ were purchased from Sigma Aldrich, UK. Sodium bicarbonate was purchased from Fisher Scientific (UK). Calcium chloride dihydrate, sodium chloride, sulphuric acid, hydrochloric acid and phenol were purchased from Sigma-Aldrich (UK), All materials were used as received. Fresh porcine cornea was donated by a local abattoir.

\subsection{Preparation of Simulated Lacrimal Fluid}

Simulated lacrimal fluid (SLF) was used in the evaluation of the formulation. Correct amount of $\mathrm{NaHCO}_{3}(0.023 \mathrm{M}), \mathrm{CaCl}_{2} .2 \mathrm{H}_{2} \mathrm{O}(0.001 \mathrm{M})$ and $\mathrm{NaCl}(0.114 \mathrm{M})$ were dissolved in in 500 $\mathrm{ml}$ deionized water with continuous stirring for 30 minutes [13]. The $\mathrm{pH}$ of the solution was 7.5 .

\subsection{Phase Solubility Studies}

Conventional phase solubility studies were conducted according to Higuchi and Connors method [14] to show how CD influences the solubility of a drug [15]. For performing phase solubility studies, samples were prepared by adding excess amount FBP to $10 \mathrm{ml}$ SLF (pH 7.5) in sealed glass containers containing $0,5,1,2,5$, and $10 \%(3.4,6.8,13.7,34.2,68.5$ and 137 $\mathrm{mM})$ of $\mathrm{H} \beta \mathrm{CD}$. The solutions were mixed at a constant temperature $\left(25^{\circ} \mathrm{C}\right)$ for 24 hours using electromagnetic stirrer at $200 \mathrm{rpm}$. The solutions were then filtered (pore size $0.45 \mu \mathrm{m}$ ) and diluted accordingly. The solutions were analysed spectrophotometrically ( $\lambda \max 247 \mathrm{~nm}$ ) to 
determine the drug concentration. A phase solubility diagram was created by plotting the concentration of total dissolved drug against the concentration of $\mathrm{H} \beta \mathrm{CD}$.

\subsection{Experimental Setup for Rheological Measurements}

All rheological measurements were performed using Kinexus Rheometer (Malvern Panalytical) fitted with a $40 \mathrm{~mm}$ serrated plate geometry. A circulatory system was used for the analysis which contained a modified rheo-dissolution cell attached to the lower plate of the geometry (fig 1).

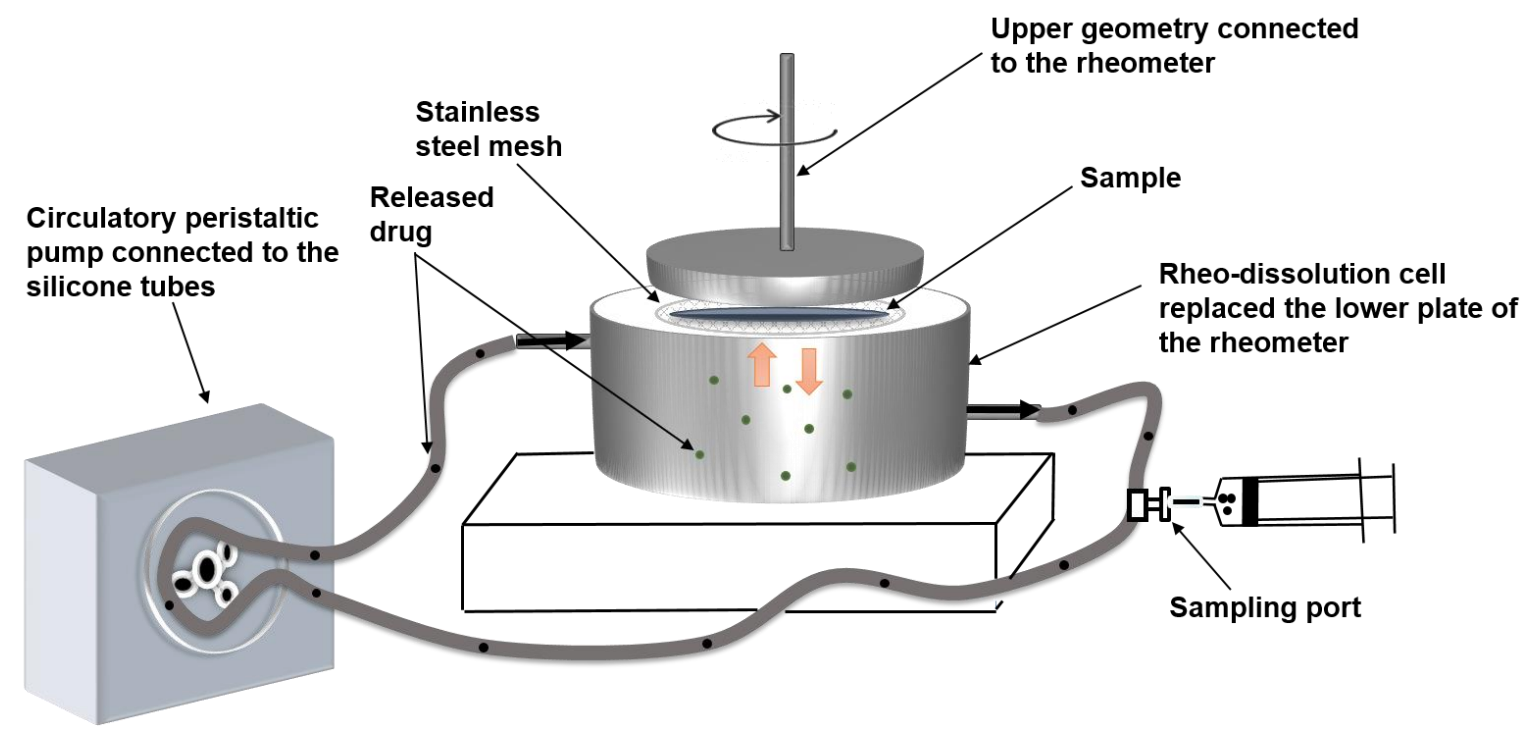

Fig. 1. Schematic diagram of the experimental set up of rheo-dissolution cell which replaced the lower plate of rheometer and connected to a peristaltic pump (adapted from [12])

The cell was constructed from acrylonitrile butadiene styrene using a Makerbot Replicator ${ }^{\mathrm{TM}}$ 2 3D printer (New York, USA). The circular cell was designed with an opening top covered with a stainless steel mesh where the sample was placed. The cell was connected to a circulating peristaltic pump (flow rate of $1 \mathrm{ml} / \mathrm{min}$ ) to maintain the flow of SLF ensuring sink conditions. Gelation was induced by injecting the SLF into the flow through system, which allowed the ions of SLF to come into contact with the sample in situ. The rheological studies were evaluated 
in terms of elastic modulus $\left(\mathrm{G}^{\prime}\right)$ and viscous modulus $\left(\mathrm{G}^{\prime \prime}\right)$ at a frequency of $1 \mathrm{rads}^{-1}$ and $0.5 \%$ strain which was within the linear viscoelastic region.

\subsection{Interaction Studies between HßCD and Gellan gum}

$\mathrm{H} \beta \mathrm{CD}$ solutions were prepared by adding the appropriate amounts of $\mathrm{H} \beta \mathrm{CD}$ in deionized water at room temperature to prepare $0.5 \%, 1 \%, 2 \%, 5 \%$ and $10 \% \mathrm{w} / \mathrm{v}$ final concentration. The $\mathrm{H} \beta \mathrm{CD}$ solutions were then heated up to $85^{\circ} \mathrm{C}$ and gellan gum was added while stirring at $500 \mathrm{rpm}$ to produce $0.4 \% \mathrm{w} / \mathrm{v}$ final gellan concentration. $0.4 \%$ concentration was selected according to the marketed Timoptol LA®. Once the gellan was dissolved, stirring was stopped and solutions were allowed to cool at room temperature. Oscillatory rheological analysis in terms of $\mathrm{G}^{\prime}$ and $\mathrm{G}^{\prime \prime}(\mathrm{Pa})$ were carried out using the experimental set up described in 2.4 to examine the gelation behaviour of gellan gum in presence of different concentration of $\mathrm{H} \beta \mathrm{CD}$.

\subsection{Preparation of In Situ Gel Forming Ophthalmic Formulation of FBP with HBCD and Gellan Gum}

In the majority of $\mathrm{CD}$ based eye drop formulations investigated for clinical evaluation, $10 \%$ to $30 \%$ w/v of CD was used for solubilisation of the drugs [16-20]. However, to prepare the formulation, required quantities of $\mathrm{H} \beta \mathrm{CD}$ was added to deionized water at room temperature. Precise amount of FBP $(0.029 \%)$ was added to the solution based on the marketed product Ocufen ${ }^{\circledR}$ which contains FBP sodium $0.03 \%$ w/v. Once dissolved, the solution was heated to $85^{\circ} \mathrm{C}$ while stirring and required amount of gellan gum was added to prepare a $0.4 \% \mathrm{w} / \mathrm{v}$ solution. The stirring was stopped after complete dissolution of gellan gum and the formulation was cooled to room temperature. The $\mathrm{pH}$ of the prepared formulations was 4.3 . It should be noted that the buffering action of lacrimal fluid in vivo depends on the chemical buffering capacity which is $0.434 \mathrm{~mol} / \mathrm{L} / \Delta \mathrm{pH}$. So it can be assumed that $25-30 \mu \mathrm{l}$ formulation of $\mathrm{pH} 4.3$ will not interfere with the physiological $\mathrm{pH}$ of $30 \mu \mathrm{l}$ (maximum volume of lacrimal fluid in culde-sac) lacrimal fluid and therefore should not cause any irritation if applied to the eye surface 
due to any $\mathrm{pH}$ disturbance. In these preliminary studies, the formulations were not sterilized and no antimicrobial preservatives were added.

\subsection{Confirmation of Complexation}

Thermal analysis was performed using differential scanning calorimetry (DSC) to confirm the complexation between drug and H $\beta C D$ (Mettler Toledo, DSC 1, STARe system). The formulations of FBP-H $\beta C D$ and $\mathrm{FBP}-\mathrm{H} \beta \mathrm{CD}$ with gellan were prepared for freeze drying. The formulations were stored in a freezer at $-20^{\circ} \mathrm{C}$ for overnight. The frozen samples were then dried using a (Christ Alpha 2-4 L Dplus) freeze drier. The drying procedure was performed for 24 hours at $-84.6^{\circ} \mathrm{C}$ with the vacuum set at 0.001 mbar. DSC measurements were performed on all the samples (FBP, gellan, $\mathrm{H} \beta \mathrm{CD}$, physical mix and freeze dried samples) following the method described by Pralhad and Rajendrakumar (2004) [21]. Briefly, samples were accurately weighed (Mettler AT201) and heated in crimp sealed aluminium pans at $10^{\circ} \mathrm{C}$ per min between 50 to $150^{\circ} \mathrm{C}$. The nitrogen gas flow was $200 \mathrm{ml} / \mathrm{min}$. Thermograms of FBP, $\mathrm{H} \beta C D$, gellan, physical mix were compared with the freeze dried samples.

\subsection{Simultaneous Determination of Rheology and Dissolution of the Drug (Rheo- dissolution study)}

Rheo-dissolution studies were performed using the experimental setup described in section 2.4. The samples were allowed to form gels in situ in presence of SLF and measurements of $\mathrm{G}^{\prime}$ and $\mathrm{G}^{\prime \prime}$ were performed as an indication of gelation. To measure FBP release during the rheological analysis, aliquots of SLF were withdrawn at pre-determined time intervals $(60,120,180,240$ and $300 \mathrm{~min}$ ) and replaced with equal amount of fresh SLF. Collected samples were diluted and analysed using UV spectrophotometer (Agilent Cary $60 \mathrm{UV}-\mathrm{Vis}$ ) at $247 \mathrm{~nm}$. The percentage of FBP released from the in situ gel was determined from linear regression equation obtained from the UV standard calibration curve. All experiments were performed in triplicate. 


\subsection{H HCD Dissolution Studies}

$\mathrm{H} \beta \mathrm{CD}$ release was measured using phenol-sulphuric acid assay on the withdrawn samples as reported previously [22]. Briefly, $1 \mathrm{ml}$ of $0.5 \%$ phenol solution was added to the filtered samples $\left(1 \mathrm{ml}\right.$ ) followed by adding $5 \mathrm{ml}$ of concentrated $\mathrm{H}_{2} \mathrm{SO}_{4}$ and mixed vigorously for 10 $\min$. The resultant solutions were placed in a water bath at $25-30^{\circ} \mathrm{C}$ for $20 \mathrm{~min}$. The solutions were analysed at 490 using UV spectrophotometer [23]. The concentration of H $\beta C D$ dissolved from the sample was determined from a standard calibration curve.

\subsection{Ex- vivo Permeation Studies using Porcine Cornea}

Permeation studies were conducted for the formulation containing $10 \% \mathrm{H} \beta \mathrm{CD}$ and marketed Ocufen ${ }^{\circledR}$ eye drop (pH 6.68) formulation. Corneas used in the permeation studies were obtained from fresh porcine eye balls. The fat and muscles around the eye balls were trimmed and an incision was made between optic nerve and cornea. The sclera was cut all the way around the cornea and the vitreous humor, lens and ciliary body were removed. Finally, the cornea was removed carefully to avoid any distortion (method adapted from Fatahalla et al., 2016) [24]. Permeation studies were performed using Franz diffusion cells containing a $4 \mathrm{ml}$ fixed volume receiver compartment with a sampling port. The diffusion surface area of the cell was $1.76 \mathrm{~cm}^{2}$, where the cornea was placed between the donor and receiver compartments. It was possible to place the cornea flat on the diffusion surface area. The endothelial side of the cornea faced the receiver compartment. The receiver compartments were filled with $\mathrm{SLF}(\mathrm{pH} 7.5)$ and $35^{\circ} \mathrm{C}$ was maintained throughout the experiments with a magnetic stirrer bar used to ensure an isothermal temperature was maintained throughout the receiver fluid. Test samples, were placed directly on the cornea in the donor compartment and samples of the receiver fluid were withdrawn at different time intervals and were replaced with fresh medium. The amount of FBP permeated across the cornea was determined by the UV spectroscopy. Three corneas were used $(n=3)$ for each of the formulations. 


\subsection{Statistical Analysis}

The results were expressed as mean \pm standard deviation $(n=3)$, were statistically analysed using a Student's t-test for paired data. Statistical significance was accepted where $\mathrm{P}<0.05$.

\section{Results and Discussion}

\subsection{Phase Solubility Studies}

To initially determine how $\mathrm{H} \beta \mathrm{CD}$ influenced the solubility of FBP, phase solubility studies were performed. These experiments revealed that the solubility of FBP increased linearly with increased amount of $\mathrm{H} \beta \mathrm{CD}$ (fig 2). The solubility of FBP was $48.53 \mathrm{mM}$ at maximum concentration of $\mathrm{H} \beta \mathrm{CD}(137 \mathrm{mM}$ or $20 \%)$ which was in good agreement with the reported solubility of FBP in phosphate buffer system ( $\mathrm{pH}$ 7.4) by Felton et al., (2014) [6]. According to Higuchi \& Connors [14], the graph was type A which indicated the formation of a soluble complex. The linear portion of the graph $\left(\mathrm{R}^{2}=0.9934\right)$ indicated $A_{L}$ type and allowed us to assume that 1:1 inclusion complex of FBP-H $\beta C D$ was present in the media. $0.029 \%(1.23$ $\mathrm{mM}$ ) was selected as a concentration of FBP for the final formulation based on Ocufen ${ }^{\circledR}$ eye drops. Although it was apparent that any concentration of $\mathrm{H} \beta \mathrm{CD}$ ranging from $3.4(0.5 \%)$ to $137 \mathrm{mM}(20 \%)$ was able to solubilize $1.23 \mathrm{mM}$ of FBP, the time taken for this to occur varied considerably. At concentrations above $34.2 \mathrm{mM}(5 \%) \mathrm{H} \beta \mathrm{CD}$ solubilisation took approximately 30 minutes whereas at concentrations less than $34.2 \mathrm{mM}$ required stirring overnight to fully solubilise the FBP. Therefore, further experiments were performed using $68.5 \mathrm{mM}(10 \%)$ and $137 \mathrm{mM}(20 \%)$ of $\mathrm{H} \beta \mathrm{CD}$. 


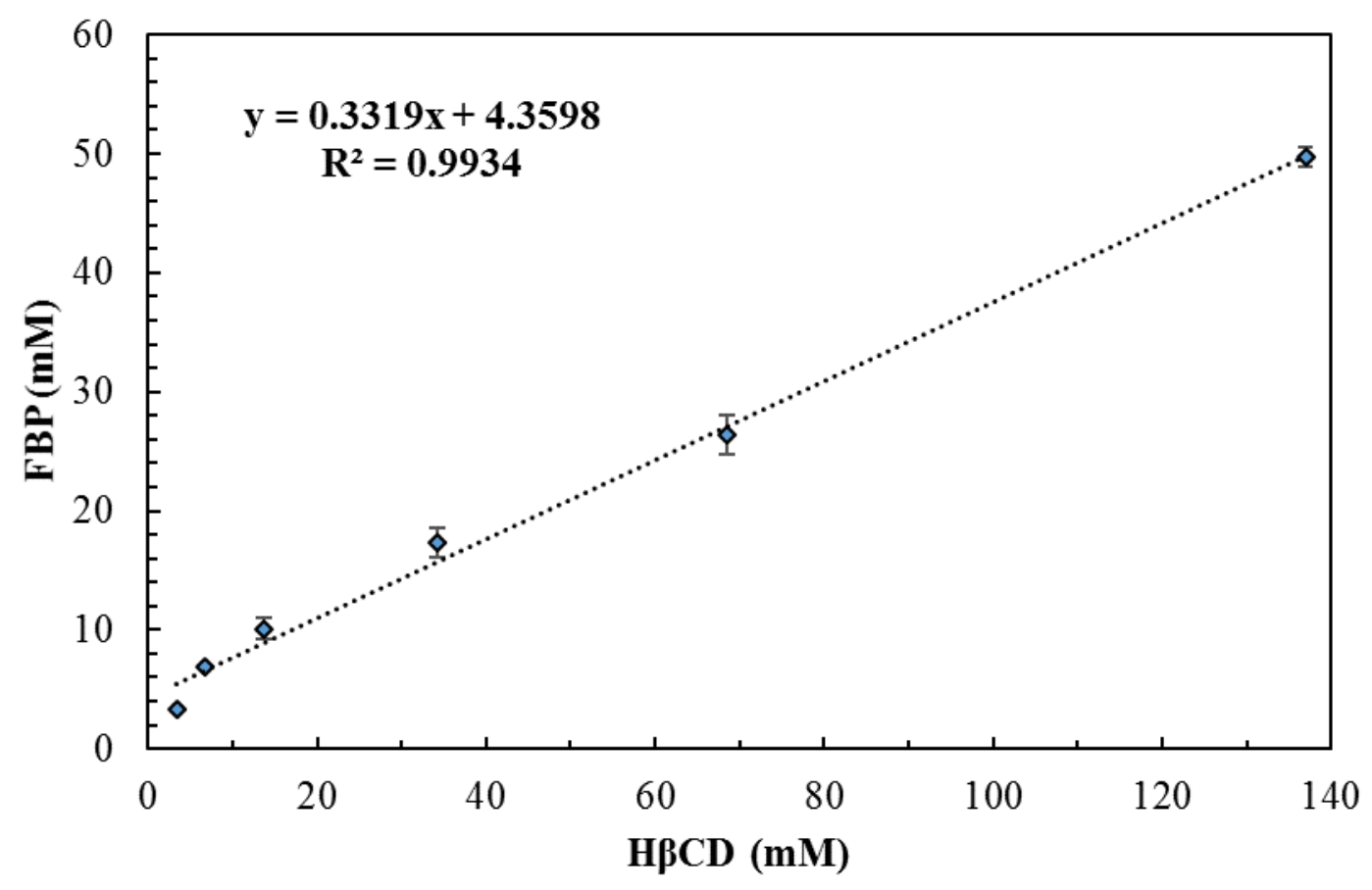

Fig. 2. FBP solubility as a function of HßCD

\subsection{Interaction Studies between HßCD and Gellan Gum}

Oscillatory rheological analysis was performed to examine the in situ gelling behaviour of the polymer upon contact with SLF and to determine if the presence of H $\beta C D$ caused any changes in gelation behaviour (fig 3). Figure 3A shows the viscoelasticity of $0.4 \%$ gellan on exposure to SLF where the onset of gelation was fast (within $2 \mathrm{~min}$ ) and $\mathrm{G}^{\prime}$ was significantly dominant over $\mathrm{G}^{\prime \prime}$ with a terminal value of $\sim 320 \mathrm{~Pa}$. Addition of increasing concentration of $\mathrm{H} \beta \mathrm{CD}(0.5$, $1,2,5$ and $10 \%$ ) to the gellan solution did not alter the rheological characteristics of gellan in terms of onset of gelation and average final gel strength of $\sim 310 \mathrm{~Pa}$ indicated an absence of physical interactions between gellan and $\mathrm{H} \beta \mathrm{CD}$. 

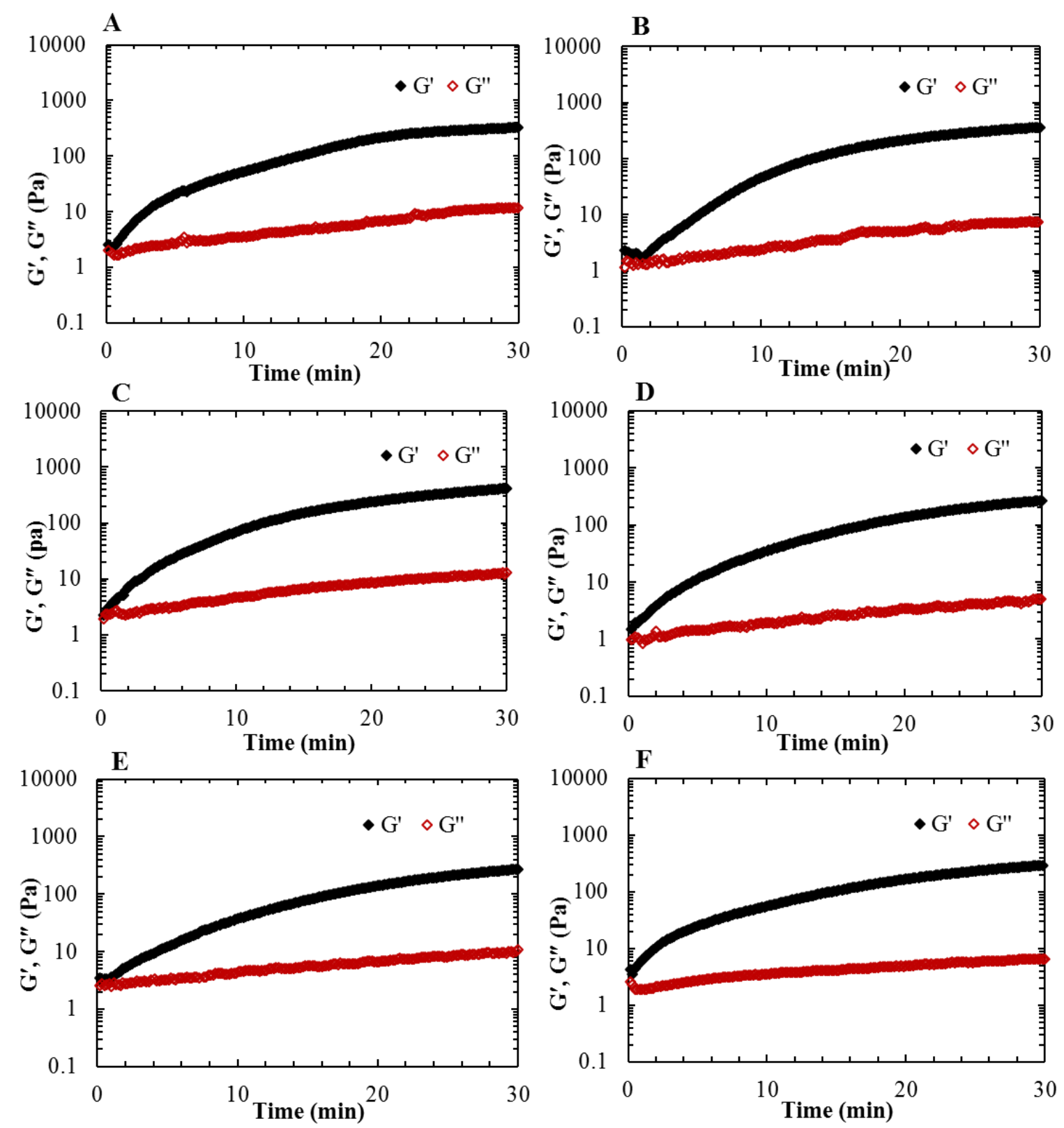

Fig. 3. In situ gelation of $0.4 \%$ gellan showing $G^{\prime}$ and $G^{\prime \prime}$ on exposure to SLF (A) $0.4 \%$ gellan only and in the presence of (B) $0.5 \% \mathrm{H} \beta C D$ (C) $1 \% \mathrm{H} \beta C D$ (D) $2 \% \mathrm{H} \beta C D$ (E) $5 \%$



\subsection{Confirmation of Complexation by DSC}

Thermal analysis was conducted to confirm the complexation of FBP- H $\beta C D$ with gellan. Thermograms of FBP, gellan and $\mathrm{H} \beta \mathrm{CD}$ alone, physical blends and the freeze dried samples revealed a readily apparent melting endotherm for FBP alone and there were no melting transition for gellan and $\mathrm{H} \beta \mathrm{CD}$ as expected (fig 4). The well-defined melt transition of FBP 
appeared in the physical blends indicating incomplete complexation by $\mathrm{H} \beta \mathrm{CD}$. However, in the freeze dried samples melting endotherms were absent. The absence of this peak can be is an indication that complete inclusion complexation of FBP-H $\beta C D$ was achieved [6]. Furthermore, the thermogram of the complex with gellan indicated that gellan did not interfere with the complex formation.

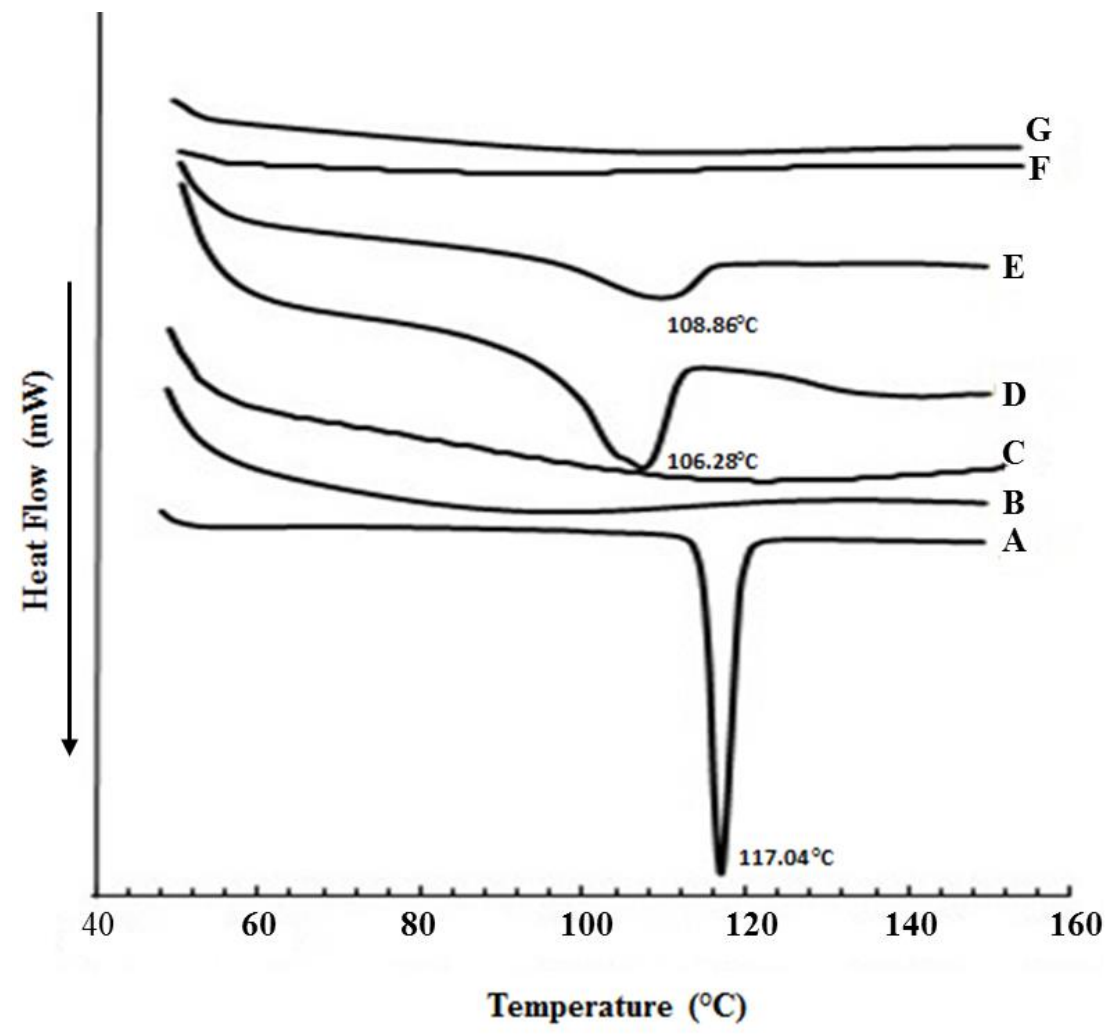

Fig. 4. DSC thermogram of (A) FBP (B) HBCD (C) gellan (D) physical mix of FBP and HBCD (E) physical mix of FBP, gellan and HBCD (F) freeze dried formulation of FBP and HBCD (G) freeze fried formulation of flurbiprofen, gellan and HPBCD

\subsection{Simultaneous Determination of Rheology and Dissolution of the Drug (Rheo- Dissolution Study)}

Following the exposure of FBP-H $\beta C D$ complex and gellan to the SLF, gelation was initiated, as indicated by an increase of $G^{\prime}$ and $G^{\prime \prime}$ over first 10 min of exposure (fig $\mathbf{5 A}$ and $\mathbf{B}$ ). The modulus reached a steady state after complete gelation with $\mathrm{G}^{\prime}>\mathrm{G}^{\prime \prime}$ indicating the formation of strong gel [25]. The FBP release curve reveals an initial burst release of FBP ( 25\% at 60 
min) while the gel was forming and the release followed a similar trend even after complete gelation. Approximately $97 \%$ of FBP was released in 300 min (fig 5A). The release curve of FBP when $20 \% \mathrm{H} \beta \mathrm{CD}$ was used showed comparatively lower release at $300 \mathrm{~min}(\sim 80 \%)$ although it was not significantly different ( $p>0.05)$ (fig 5A).
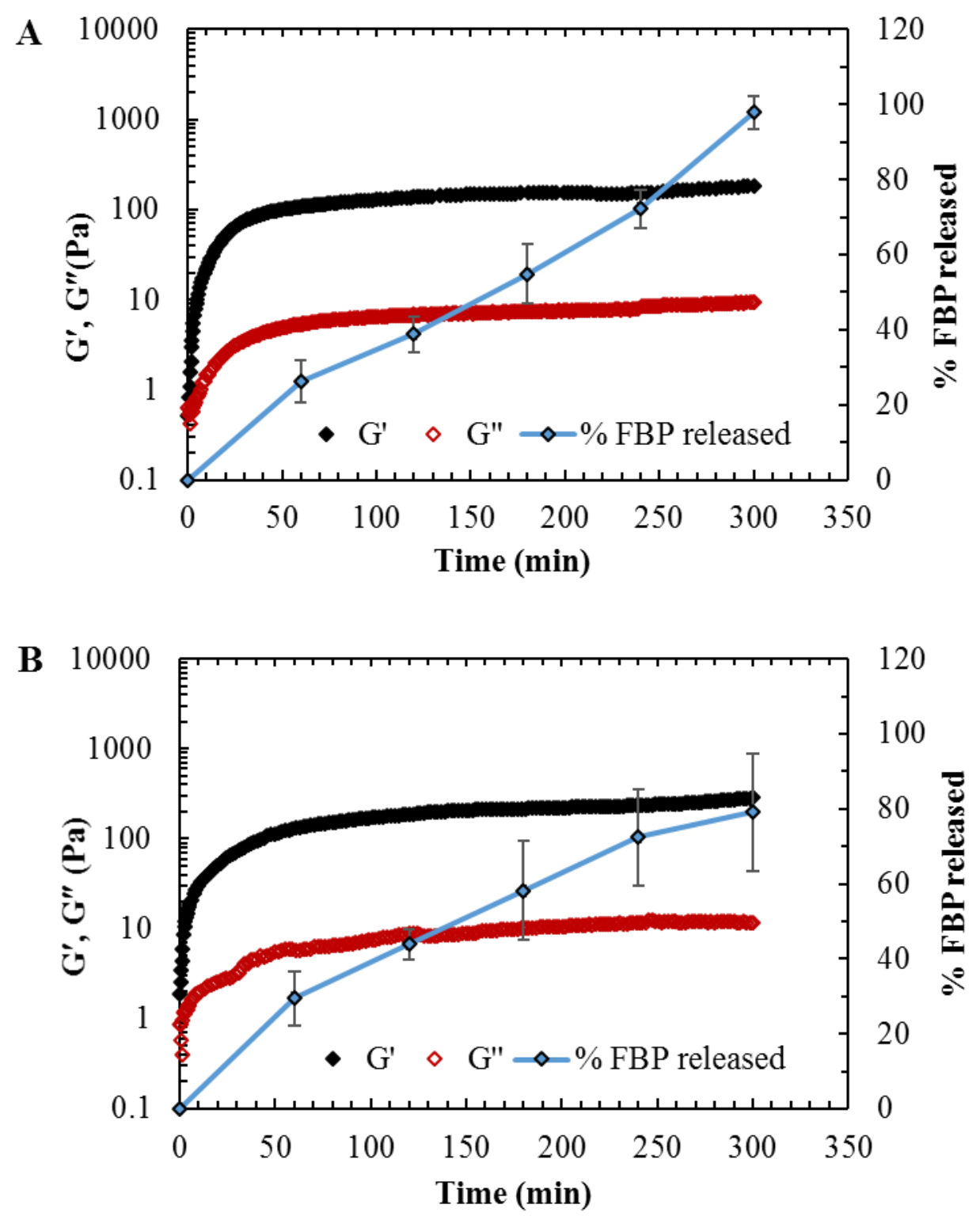

Fig. 5. Simultaneous determination of rheological changes $\left(G^{\prime}\right.$ and $\left.G^{\prime \prime}\right)$ and drug release study of the formulation containing (A) $10 \%$ HBCD (B) $20 \% \mathrm{H \beta CD}$

$\mathrm{CD}$ complexation is a dynamic process with drug molecules in a dynamic equilibrium with the $\mathrm{CD}$, constantly associating and disassociating from the complex, therefore there is always 
presence of free drug and CD complexed drug. Release of FBP from the in situ gel is thought to occur by parallel diffusion of FBP-H $\beta C D$ complexes and free drug. Once the complexes are released from the gel the FBP dissociates from the complex before dissolving into the simulated lacrimal fluid release medium, due to its higher $\mathrm{pH}(\mathrm{pH}$ 7.5) facilitating dissolution of FBP (fig 6). The amount of drug detected in the release media was dependent on the concentration of H $\beta C D$. The release of FBP was greater when $10 \% \mathrm{H} \beta C D$ was used with approximately $97 \%$ released in $300 \mathrm{~min}$ (fig 5A).

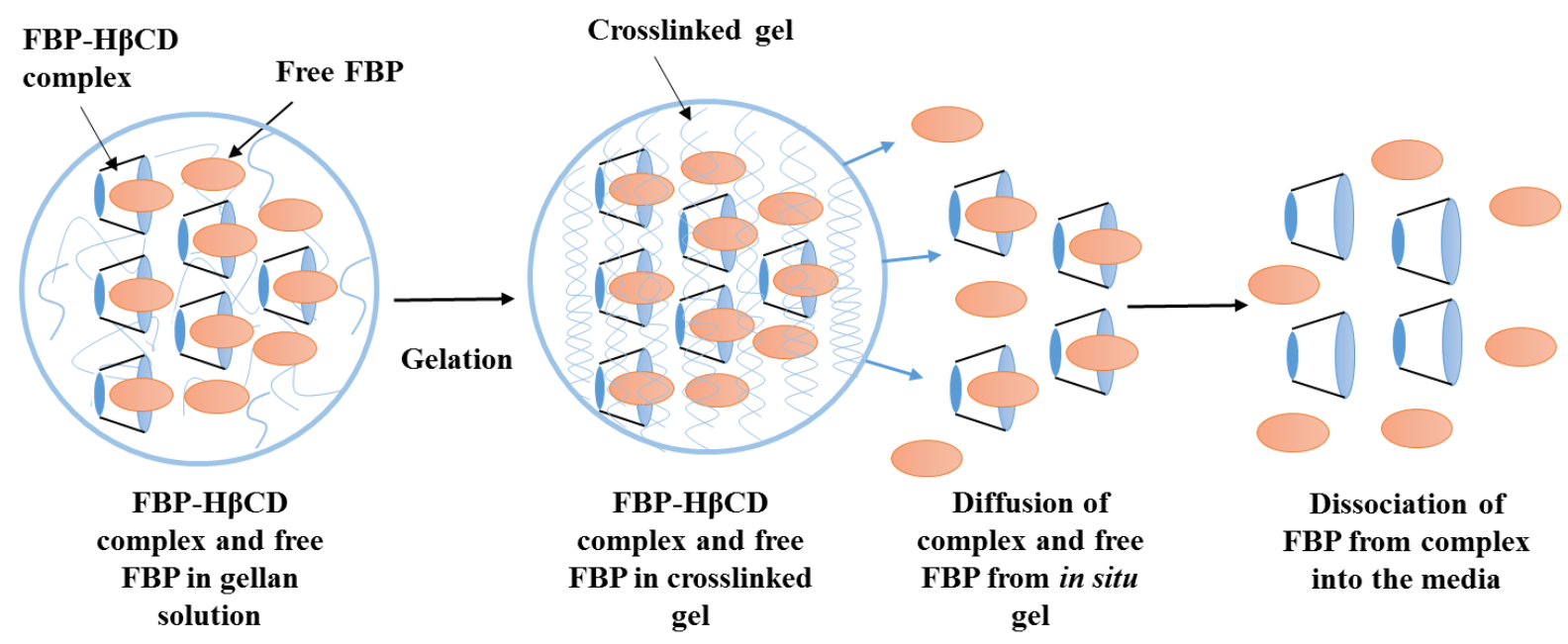

Fig. 6. Schematic representation of diffusion of FBP- HBCD complex through the gel and dissociation of FBP from the complex

The comparatively lower release of FBP from the formulation containing $20 \% \mathrm{H} \beta \mathrm{CD}$ (fig 5B) was likely due to the tendency of $\mathrm{CD}$ derivatives (like $\mathrm{H} \beta \mathrm{CD}$ ) and their complexes to selfassociate and form aggregates in aqueous solutions [26]. To investigate this, release of $\mathrm{H} \beta \mathrm{CD}$ from the in situ gel forming formulation containing varying concentration of $\mathrm{H} \beta \mathrm{CD}(10 \%$ and $20 \%$ ) was quantified using the phenol sulphuric acid assay (fig 7). 

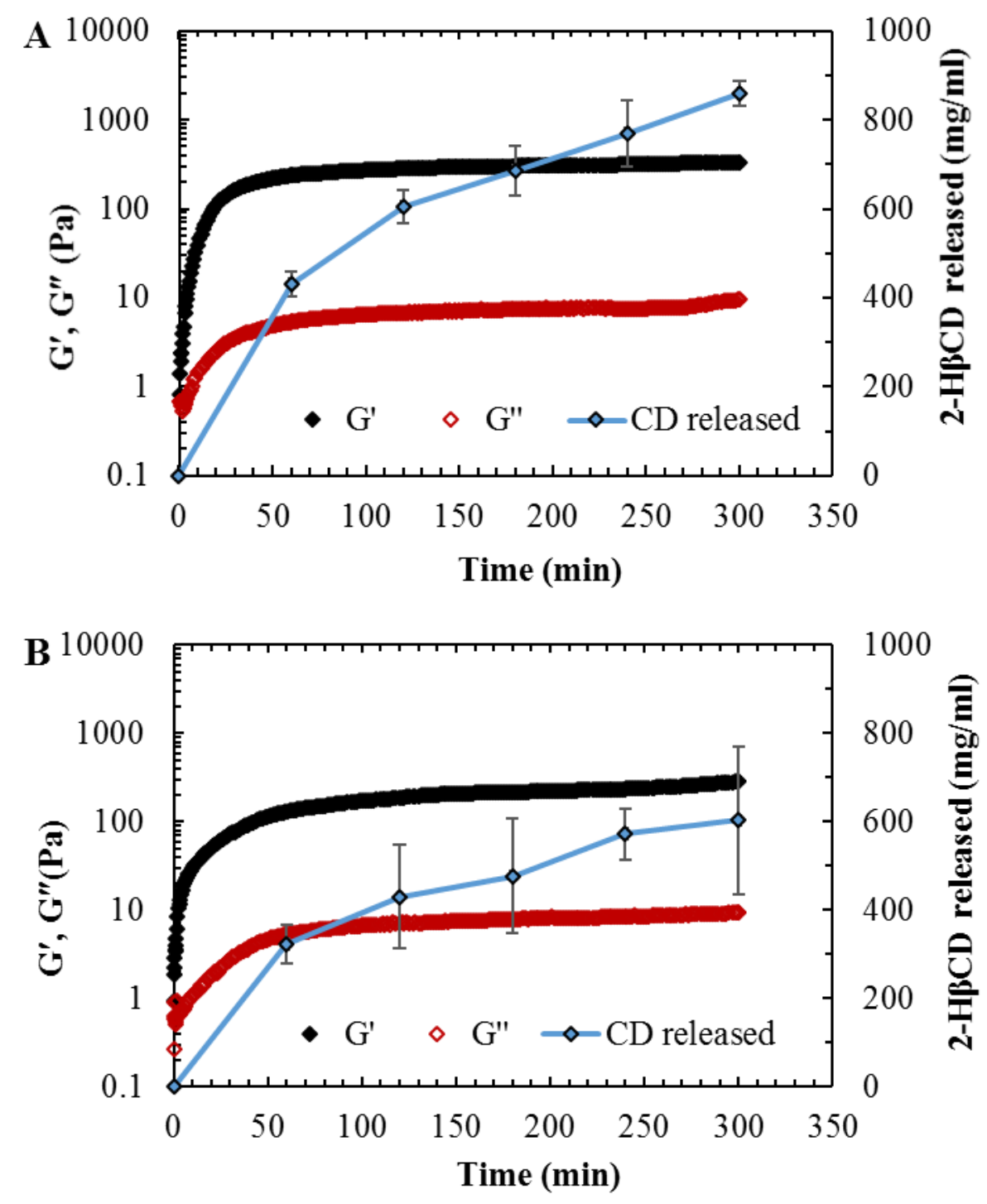

Fig. 7. Simultaneous determination of rheological changes $\left(G^{\prime}\right.$ and $\left.G^{\prime \prime}\right)$ and $H \beta C D$ release study using phenol sulphuric acid assay of the formulations containing (A) $10 \% \mathrm{HBCD}$ (B) $20 \% \mathrm{H \beta CD}$

The release of $\mathrm{H} \beta \mathrm{CD}$ from the gel containing $20 \% \mathrm{H} \beta \mathrm{CD}$ (fig 7B) was significantly lower (P $<0.05$ ) compared with the formulation containing $10 \% \mathrm{H} \beta \mathrm{CD}$ (fig 7A) supporting the explanation postulated for reduced FBP release when $20 \% \mathrm{H} \beta \mathrm{CD}$ was used. CDs self-assemble and form small clusters that can then aggregate further and form larger clusters (fig 8). The aggregates usually have a diameter between 20 to $200 \mathrm{~nm}$ and the size of the aggregates increase with increasing the concentrations of CDs [27]. Intermolecular hydrogen bonding 
between the $\mathrm{OH}$ groups of $\mathrm{CDs}$ and surrounding water molecules is the driving force for assembly and further aggregation of the molecules.



Fig 8: Schematic presentation of self-assembling of CD molecules to form small clusters that associate to create larger aggregates

There is therefore, a possibility that larger CD aggregates formed at high concentration of H $\beta C D(20 \%)$ obstructed diffusion of the free drug and smaller complexes through the gellan which resulted in reduced drug release into the medium. To demonstrate that the gellan did not dissolve into the release media and interfere measurements of $\mathrm{H} \beta \mathrm{CD}$ release, a blank rheodissolution analysis was also performed using $0.4 \%$ gellan alone. Only a negligible amount of gellan $(<4 \%)$ was detected in the release medium (data not shown) indicating that gellan did not interfere with measurements of $\mathrm{H} \beta \mathrm{CD}$ release.

\subsection{Ex-vivo Permeation Study}

The permeation study highlighted that the percentage of FBP permeated through the porcine cornea was higher in case of the formulation containing $\mathrm{H} \beta \mathrm{CD}$ and gellan compared with that of FBP sodium $\left(\right.$ Ocufen $^{\circledR}$ ) (fig 9). This can be explained by the ability of CDs' to act as carrier and deliver the unionised drug to the surface of a biological membrane [28]. 


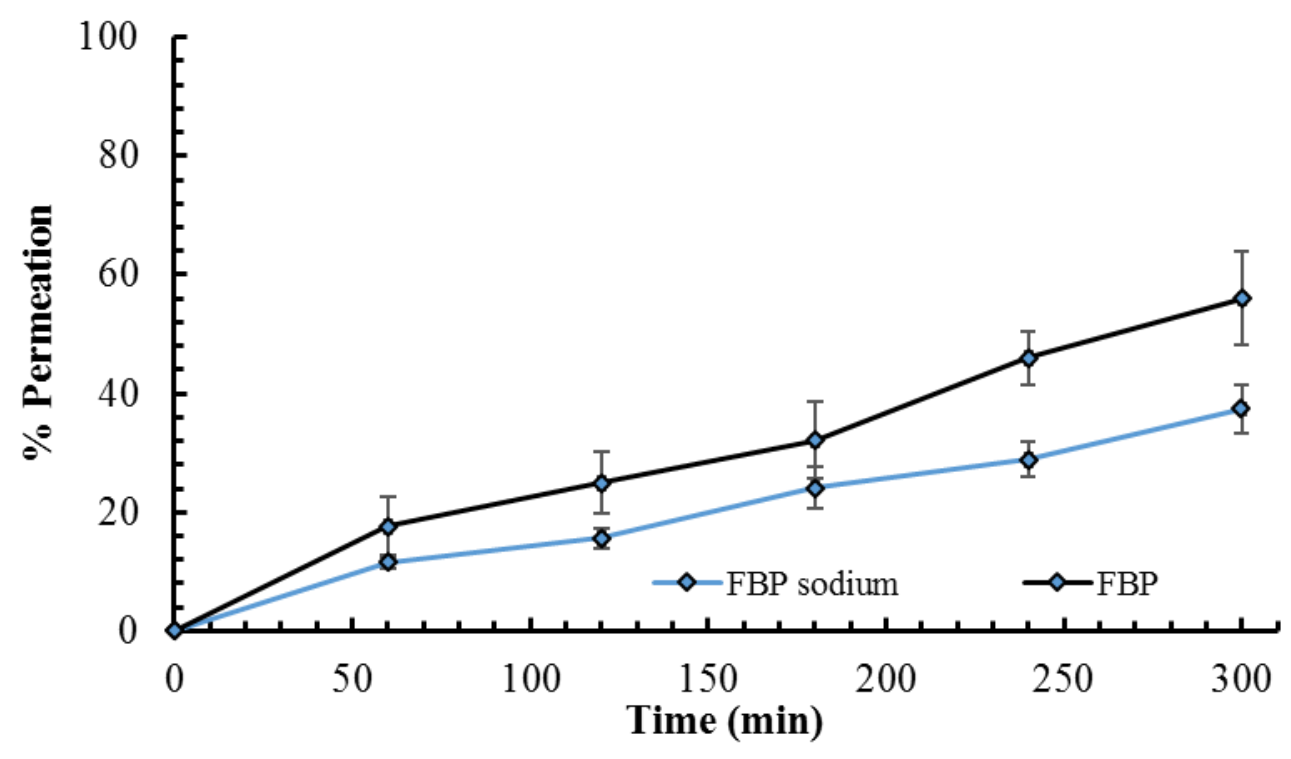

Fig. 9. Amount of FBP permeated from the formulation containing FBP with $10 \% \mathrm{H} \beta C D$ and gellan compared with the commercial product Ocufen ${ }^{\circledR}$ containing flurbiprofen sodium (n=3)

The FBP-H $\beta C D$ inclusion complex diffused through the in situ gel to the surface of the cornea and FBP then dissociated from the complex to permeate through the cornea. It is well known that free acid drugs can permeate biological membranes faster than the equivalent salt form [29]. The $\mathrm{pH}$ of the Ocufen ${ }^{\circledR}\left(\mathrm{pH}\right.$ 6.7) eye drop formulation was much greater than the $\mathrm{pK}_{\mathrm{a}}$ of

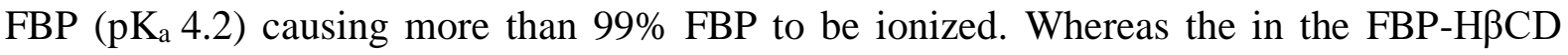
formulation the $\mathrm{pH}$ is 4.3 , which is almost equivalent to the $\mathrm{pKa}$ of the $\mathrm{FBP}\left(\mathrm{pK}_{\mathrm{a}} 4.2\right)$ delivering $\sim 50 \%$ of the drug in the unionised form, and therefore, enhancing permeability when compared with the ionised FBP in the Ocufen ${ }^{\circledR}$. This formulation approach to improving permeability of poorly soluble drugs could potentially be utilised with other water based ionotropic in situ gelling biopolymers such as sodium alginate, carrageenan or pectin.

\section{Conclusion}

This study has demonstrated a method of developing an in situ gel forming ophthalmic formulation of the poorly soluble drug FBP by forming inclusion complex with H $\beta C D$. Formation of an inclusion complex enhanced the solubility of FBP and allowed addition of 
gellan gum in order to form a gel in situ. This study also utilized a system to monitor real time gelation and dissolution of FBP simultaneously on exposure to the crosslinking solution. Data obtained from the rheo-dissolution study for the formulation containing $10 \% \mathrm{H} \beta \mathrm{CD}$ showed 97\% FBP release in 5 hours. Comparative permeation studies indicated improved permeation of FBP as a complex compared to the sodium salt of FBP. All the data obtained indicated that gellan gum did not interfere the complex formation and the complex diffused successfully through the in situ gel. Thus, this particular poorly soluble drug can be included as the free acid in the in situ gelling system by forming an inclusion complex with $\mathrm{H} \beta \mathrm{CD}$. Moreover, the ability to monitor real time gelation and drug release simultaneously, can be a useful tool when designing in situ gelling drug delivery systems.

\section{References}

[1] D. Achouri, K. Alhanout, P. Piccerelle, V. Andrieu, Recent advances in ocular drug delivery, Drug Dev. Ind. Pharm. $39 \quad$ (2013) 1599-1617. https://doi.org/10.3109/03639045.2012.736515.

[2] A.H. El-Kamel, In vitro and in vivo evaluation of Pluronic F127-based ocular delivery system for timolol maleate, Int. J. Pharm. 241 (2002) 47-55. https://doi.org/10.1016/S0378-5173(02)00234-X.

[3] J.C. Lang, Ocular drug delivery conventional ocular formulations, Adv. Drug Deliv. Rev. 16 (1995) 39-43. https://doi.org/10.1016/0169-409X(95)00012-V.

[4] T. Loftsson, E. Stefánsson, Effect of cyclodextrins on topical drug delivery to the eye, Drug Dev. Ind. Pharm. 23 (1997) 473-481. https://doi.org/10.3109/03639049709148496.

[5] M. Cirri, C. Rangoni, F. Maestrelli, G. Corti, P. Mura, Development of fast-dissolving tablets of flurbiprofen-cyclodextrin complexes, Drug Dev. Ind. Pharm. 31 (2005) 697707. https://doi.org/10.1080/03639040500253694.

[6] L.A. Felton, C. Popescu, C. Wiley, E.X. Esposito, P. Lefevre, A.J. Hopfinger, Experimental and Computational Studies of Physicochemical Properties Influence NSAID-Cyclodextrin Complexation, AAPS PharmSciTech. 15 (2014) 872-881. https://doi.org/10.1208/s12249-014-0110-2.

[7] T. Loftssona, T. Järvinen, Cyclodextrins in ophthalmic drug delivery, Adv. Drug Deliv. Rev. 36 (1999) 59-79. https://doi.org/10.1016/S0169-409X(98)00055-6.

[8] P. Jansook, P. Kulsirachote, R. Asasutjarit, T. Loftsson, Development of celecoxib eye drop solution and microsuspension: A comparative investigation of binary and ternary cyclodextrin complexes, Carbohydr. Polym. $225 \quad$ (2019) 115209. 
https://doi.org/10.1016/J.CARBPOL.2019.115209.

[9] V.J. Stella, V.M. Rao, E.A. Zannou, V. Zia, Mechanisms of drug release from cyclodextrin complexes, Adv. Drug Deliv. Rev. 36 (1999) 3-16. https://doi.org/10.1016/S0169-409X(98)00052-0.

[10] T. Loftsson, E. Stefánsson, Cyclodextrins and topical drug delivery to the anterior and posterior segments of the eye, Int. J. Pharm. 531 (2017) 413-423. https://doi.org/10.1016/j.ijpharm.2017.04.010.

[11] S. Chandran, A. Roy, R.N. Saha, Effect of $\mathrm{pH}$ and Formulation Variables on In Vitro Transcorneal Permeability of Flurbiprofen: A Technical Note, AAPS PharmSciTech. 9 (2008) 1031-1037. https://doi.org/10.1208/s12249-008-9139-4.

[12] F.G. Senjoti, M.U. Ghori, R. Diryak, B.. Conway, G.A. Morris, A.M. Smith, Rheodissolution: A new platform for the simultaneous measurement of rheology and drug $\begin{array}{lllll}\text { release, } & \text { Carbohydr. } & \text { Polym. } & 229 & \text { (2019) }\end{array}$ https://doi.org/10.1016/J.CARBPOL.2019.115541.

[13] M.R.C. Marques, R. Loebenberg, M. Almukainzi, Simulated biological fluids with possible application in dissolution testing, Dissolution Technol. 18 (2011) 15-28. https://doi.org/10.14227/DT180311P15.

[14] T. Higuchi, K. Connors, Phase-solubility techniques, in: C. Reilley (Ed.), Adv. Anal. Chem. Instrum., John Wiley \& Sons, Inc, New York, 1965: pp. 117-212.

[15] T. Loftsson, M.E. Brewster, Pharmaceutical applications of cyclodextrins: Basic science and product development, J. Pharm. Pharmacol. 62 (2010) 1607-1621. https://doi.org/10.1111/j.2042-7158.2010.01030.x.

[16] E.C. Kearse, O.L. Mcintyre, M.H. Johnson, C.I. Phillips, R. Lathe, W. Adams, K. Green, Influence of dehydroepiandrosterone on rabbit intraocular pressure, Ophthalmic Res. 33 (2001) 42-47. https://doi.org/10.1159/000055640.

[17] T. Loftsson, P. Jansook, E. Stefánsson, Topical drug delivery to the eye: Dorzolamide, Acta Ophthalmol. $90 \quad$ (2012) 603-608. https://doi.org/10.1111/j.17553768.2011.02299.x.

[18] A.H.A. Mohamed-Ahmed, A. Lockwood, H. Li, M. Bailly, P.T. Khaw, S. Brocchini, An ilomastat-CD eye drop formulation to treat ocular scarring, Investig. Ophthalmol. Vis. Sci. 58 (2017) 3425-3431. https://doi.org/10.1167/iovs.16-21377.

[19] N. Okamoto, Y. Ito, N. Nagai, T. Murao, Y. Takiguchi, T. Kurimoto, O. Mimura, Preparation of Ophthalmic Formulations Containing Cilostazol as an Anti-glaucoma Agent and Improvement in Its Permeability through the Rabbit Cornea, J. Oleo Sci. 59 (2010) 423-430. https://doi.org/JST.JSTAGE/jos/59.423 [pii].

[20] M. Tanito, K. Hara, Y. Takai, Y. Matsuoka, N. Nishimura, P. Jansook, T. Loftsson, E. Stefánsson, A. Ohira, Topical dexamethasone-cyclodextrin microparticle eye drops for diabetic macular edema, Investig. Ophthalmol. Vis. Sci. 52 (2011) 7944-7948. https://doi.org/10.1167/iovs.11-8178.

[21] T. Pralhad, K. Rajendrakumar, Study of freeze-dried quercetin-cyclodextrin binary systems by DSC, FT-IR, X-ray diffraction and SEM analysis, J. Pharm. Biomed. Anal. 34 (2004) 333-339. https://doi.org/10.1016/S0731-7085(03)00529-6. 
[22] M. Dubois, K. Gilles, J. Hamilton, P. Rebers, F. Smith, Colorimetric method for determination of sugars and related substances, Anal. Chem. 28 (1956) 350-356. https://doi.org/10.1021/ac60111a017.

[23] S.S. Nielsen, Phenol-Sulfuric Acid Method for Total Carbohydrates, in: Food Anal. Lab. Man., 2nd ed., Springer, New York, 2010: pp. 47-54. https://doi.org/10.1007/978-14419-1463-7.

[24] Z.M.A. Fathalla, K.A. Khaled, A.K. Hussein, R.G. Alany, A. Vangala, Formulation and corneal permeation of ketorolac tromethamine-loaded chitosan nanoparticles, Drug Dev. Ind. Pharm. 42 (2016) 514-524. https://doi.org/10.3109/03639045.2015.1081236.

[25] E.R. Morris, K. Nishinari, M. Rinaudo, Gelation of gellan - A review, Food Hydrocoll. 28 (2012) 373-411. https://doi.org/10.1016/j.foodhyd.2012.01.004.

[26] P. Saokham, C. Muankaew, P. Jansook, T. Loftsson, Solubility of cyclodextrins and drug/cyclodextrin complexes, Molecules. $23 \quad$ (2018) 1-15. https://doi.org/10.3390/molecules23051161.

[27] T. Loftsson, M. Másson, M.E. Brewster, Self-Association of Cyclodextrins and Cyclodextrin Complexes, J. Pharm. Sci. 93 (2004) 1091-1099. https://doi.org/10.1002/jps.20047.

[28] T. Loftsson, Increasing the cyclodextrin complexation of drugs and drug biovailability through addition of water-soluble polymers, Pharmazie. 53 (1998) 733-740.

[29] P. Minghetti, F. Cilurzo, A. Casiraghi, L. Montanari, A. Fini, Ex vivo study of transdermal permeation of four diclofenac salts from different vehicles, J. Pharm. Sci. 96 (2007) 814-823. https://doi.org/10.1002/jps.20770. 